\title{
Music, History and the Human Psyche: A Critique of Salman Rushdie's The Ground Beneath Her Feet
}

\author{
KinshukChakraborty ${ }^{1^{*}}$ \\ ${ }^{1} \mathrm{PhD}$ Scholar,Department of English , Assam University, Silchar.
}

\begin{abstract}
Culture and its ramifications, since time immemorial, have been hot seats of debates and negotiations. The myriad nuances which are associated with any culture for that matter glaringly and very rightly finds true expression in various kinds of fiction. Salman Rushdie has always emerged as one of the notable writers who is known for the enticing yet subtle amalgamation of different genres of writing in his so called "cult" pieces of artistic creation. Talking about a cult text, what better can fit in than the everpopular The Ground Beneath Her Feet which makes one glued to the seat. Starting from the elements of history to the pivotal roles played by different songs and musical notes, the novel encapsulates them, thereby making the text a rich hotchpotch of schemas. However, what elevates the oeuvre of the piece is the inherent dealings with the psychological traits of human beings. This paper is an attempt to bring in the attributes of history and music to the forefront without neglecting the attributes of the human psyche. It also efforts to portray how distorted an individual can turn out to be with an improper psychological state of mind.
\end{abstract}

Keywords

culture, cult, history, music, psychology

\section{Introduction}

Rudimentarily speaking, the modern Indian writing, considering fiction in particular, has always emerged to be one of diversity and diverse themes. What this diversity in the context of modern Indian fiction basically be studied as is the presence of numerous themes, genres, mythological attributes, the cultural ramifications. Having said that, if one probes deep into the heart of a particular literary piece, it can easily be uncovered that modern day Indian fiction is the sheer conglomeration of ancient traditions, be it mythological inclusions or cultural traits and beliefs as such, and the modern day newly emerging societal ramification in the form of pop numerous sub-cultures of counter-cultures which lie out in the open waiting to be employed. On the flipside though, there is another framed but quite related interpretation of the same. We all agree to the fact that the modern day world of writing is a one of re-reading and re-interpreting. As a product of such a cultural frame of mind, the various amalgamations of the ancient traditions with the newly emergent modern traits led to the creation of new modern forms which not only reiterates diversity but also, at the same time, well and truly grant a contemporary outlook to an otherwise dilapidated mythical or cultural form.

Well entangled amidst the inextricably intertwined thread of culture, myth and human psyche is the concern of identity which we, the human beings, in general, dearly love. It would really be a reductionist approach of reading or rather understanding Salman Rushdie's The Ground Beneath Her Feetas something only concerned with the combination of myth with modern day culture of pop music. There are diverse layers of thoughts which are deeply rooted in one's mind or more precisely, the psyche which lend altogether a dimension to the text with its nuances leading to multiple themes and ideas at the same time. If the musical notes in the text serve the purpose of literal delineation of the ideas of intermingling of two genres, they also, very rightly, deal with the critical concepts of migration of individuals coupled with the concerns related to identities as well.

The postmodern society is a society which is known for its codes and signals. As if the cultural turn in this age has given way to the emergence of the so called popular industry at a drastic level thereby ushering in numerous forms and parts alongside the ever present idea of popularity which is associated with stardom in general. The distinction between the general idea of who is a star along with what celebrity actually is made by $\mathrm{Su}$ Holmes and Sean Redmond (2010) is of tremendous importance in the context of the novel- 
Film studies in particular has historically used the term 'star' [...] to refer to a representational interaction between the on/off-screen persona. In comparison works outside film studies have more often used the term 'celebrity' to indicate a broad category, which defines the contemporary state of being famous. [...] but what generallyunites the work on stardom and celebrity is the agreement that celebrity or fame does not reside in the individual: it is constituted discursively 'by the way in which the individual is represented.' (p. 4)

Salman Rushdie needs no separate introduction in the field of Anglo-Indian fiction and the very popularity of the text has a great connection with the humongous personality which this figures possesses. Simply put, The Ground Beneath Her Feetis the use and reuse of the ancient myth of Orpheus and the modern day culture related to the world of pop music. But the storyline is granted a very rich and attractive structure by the captivating rich narration which weaves along with the plot other tales dealing with issues associated with one's identity in general. What strikes in the minds of the general readers is the very aspect of the psychological concerns related to one's identity along with the attached aspect of popularity and fame with inevitable come along the path of success. However, it is the aspect of myth which reigns absolutely supreme in the context of the entire storyline of the novel. Not only the delineation with the different attributes of mythical depictions helps in the final outcome of the underlying theme of the novel but also, subtly albeit, heightens the newness which modern readers attribute in the postmodern society considering a particular text. Although there have been numerous interpretations given in order to comprehend the definition of a myth, the definition given by Don Cupitt (1982) always appears to be intriguing. Myth for him is

"traditional sacred story of anonymous authorship and archetypal or universal significance which is recounted in a certain community and is often linked with a ritual [...] it tells the deeds of superhuman beings such as gods, demigods, heroes, spirits or ghosts [...] it is set outside historical time in primal or eschatological time or in the supernatural world. [...] The work of myth is to explain, to reconcile, to guide action or to legitimate. We can add that myth making is evidently a primal and universal function of the human mind as it seeks a more or less unified vision of the cosmic order, the social order and the meaning of the individual's life. (p. 29)

Objectives: The following objectives will be envisaged for the research work:

1. To address the clear conglomeration of the intricacies of myth in relation to the present day contemporary culture associated with pop music. Doing this will also focus on the inherent ideas of the basic trait of the concerns related to the identity of an individual.

2. To unmask the ramifications of love which is utterly forbidden in nature and the resultant aspect of displacement, both psychologically and physiologically in relation to the characters in the novel. Thus, it will also slightly dwell on the fact that the tale which we find in the novel is a captivating alternation of the mythical tale associated with Eurydice and Orpheus.

3. To also slightly dwell on the aspect of the incest in the text so that the entire themes get portrayed in a full-fledged manner thereby making the dualities in the text vividly evident. In relation to this objective, the remark made by David McCutchion is of paramount importance,

"A compelling and authentic theme is also available here for the Indian writer in English, for his very choice of mediumreveals him as a victim of that crisis of identity which afflicts all westernized Asians and Africans-how to be modern without losing native roots, without becoming an imitation Westerner." (p. 305)

4. To dwell on the glaring issues in relation to the psychological side of the individual side of the characters in the novel. This also heightens the fact that the novel is multifarious in nature which is adorned with numerous themes and ideas.

Research Methodology: The research is planned to be based on the following methods:

1. The research is primarily based on qualitative approach. It focuses on the textual and critical analysis of the novel. This method abundantly 
helps uncover the intricacies of the research objectives.

2.The research is descriptive in design. So the descriptive outlook paved the way for in a way fulfilling the general aim of the research of bringing out the glaring relation between ancient myth and the modern day culture.

3. Theoretical analysis of the plot of the novel forms another key method for coming to a conclusion of the research objectives there this novel contains numerous attributes of themes and ideas in relation to diverse theories associated with human psyche, theories of migration and also displacement.

Hypothesis: The thesis will use the basic hypothesis thatSalman Rushdie's The Ground Beneath Her Feet is a diverse text with nuanced layers of themes related to the ancient myth, identities and issues related to migrating individuals and displaced individuals. What these substantiate is the fact that the text is basically a hot seat of interaction of numerous issues dealing with the psychology of an individual in general which again has glaring role to play in the final convergence of the themes in the novel.

Discussion:The core argument which can be put forward taking the presence of diverse themes in the novel is that the various characters which are seen to be utter struggling in relation to the search of their own selves is undoubtedly a direct result of the sense of displacement. Thus, the distorted selves coupled with a lack of sense of belonging is what form the general core of the inherent other surrounding ideas in the novel. To heighten this attribute of the so called torn apart selves of the individuals in the text, the aspect of incest plays a major role both a personal level in relation to the characters in the novel and also at a structural level in terms of the movement of the plot of the text.

"...there is also this mighty conflict between the fantasy of Home and the fantasy of Away, the dream of roots and the mirage of the journey. And if you are OrmusCama, if you are VinaApsara, whose songs could cross all frontiers, even the frontiers of people's hearts, then perhaps you believed all ground could be skipped over, all frontiers would crumble before the sorcery of the tune." (The Ground Beneath Her Feet, p. 55)

OrmusCama and VinaApsara, the two notable heroes which are found in the text play a pivotal role in relation to the aspect of numerous lyrical notes in the novel. They not only form the spokesperson of Rushdie in terms of presenting the arguments but also, they heighten the core issue of displaced selves in the text. What is found is that these two fictional characters are seen to be migration to the highly sophisticated London in the 60s and it marked the very quest of the crisis in relation to the identity of an individual. Thus, history plays a very important role in this regard. Their so called famous VTO group instantly turns out to be super hit success ushering in a lot of name and fame which finally culminated in both of them falling in love with each other. The psychological side of the characters come to the forefront both in terms of inclination towards each other and also the fact of the instability of the mind of Ormus after the fatal demise of his love, Vina in 1989 as shown in the novel which marks the advent of doom for the characters.

If we take into account of the theory of psychoanalysis in general, then the fact of some illusory and random thoughts engulfing our mind cannot really be neglected. These thoughts really play detrimental roles when it comes to delineating the insecurities which an individual suffers from in the broader domain of the peace of mind. Talking about the various proponents of the theory of psychoanalysis in general, the humongous aura of the master himself, Sigmund Freud is a matchless deal. Broadly speaking, Freudian psychoanalytical theory roughly hinges on the attributes of two notable dualities, the conscious (ego) and the unconscious (id). W.H. Auden made a very significant comment considering the great role played by Freud in the field of psychoanalytical theory, "“If often he was wrong and, at times absurd, to us is no more a person now but a whole climate of opinion under whom we conduct our different lives..." (1991, p. 22).

Both OrmusCama and VinaApsara greatly find themselves caught between the web of id, ego and sometimes superego as well in their various course of journey in the novel. Rushdie describes 
Ormus in the following manner in the text, "a musical sorcerer whose melodies could make city streets begin to dance and high buildings sway to their rhythm, a golden troubadour the jouncy poetry of whose lyrics could unlock thevery gates of Hell" (The Ground Beneath Her Feet, p. 89). The psychological sides of both the characters appear very blatantly with their depiction in a semi-naked manner on the cover of their famous album related to musical songs, "Doctor Love and the Whole Catastrophe"-

"On the sleeve he and Vina posed in the fig-leaved nude, like classical statues wearing shades. Like mythical lovers, Cupid and Psyche, Orpheus and Eurydice, Venus and Adonis. Or amodern pair. $\mathrm{He}$ was Doctor Love and she, in this reading, was the Whole Catastrophe." (The Ground Beneath Her Feet, p. 422)

Another notable longing of Ormus for Vina again finds vivid expression when he rejected all the girls which were in a way the potential candidates for her after her death. In this regard, the notable critical idea "desire" by the famous French psychologist, Jacques Lacan can easily be cited. What is remarkable is the fact that according to Lacan, the psychological traits are acquired by a human being during the period of infancy which he terms as the "mirror stage." He in a way does not align himself with the Freudian idea of dreams and wish fulfilment. According to Lacan, dream is nothing but "expression of an unconscious desire" (1981, p. 22). The glaring comparison which Rushdie makes of Ormus with the death of Orpheus is really staggering both in relation to the mythical connections and also the psychological traits of Ormus-

"Ormus, holding himself aloof from all blandishments, even engenders violence in some women who think it unreasonable of him to deny himself, who espy in his rejection of them an insult to red-blooded women everywhere. Threats are received, and the policing of VTO concerts, as well as security at the Rhodopé Building, is stepped up as a result. Such bacchicfury is one part of the temper of the times." (The Ground Beneath Her Feet, p. 393).

Conclusion: The Ground Beneath Her Feet, in a nutshell, can easily be said to be one of the captivating masterpieces of the modern day Indian fiction which not only helps understand the basic intricacies of the amalgamation of diverse themes and attributes but also, quite clearly proves the text to be one dealing with the concerns related to the identity of an individual in general. Talking about identity, the text hinges on the idea given by the great psychologist, Carl Gustav Jung who argued that the identity of an individual greatly gets formed by the various factors who in turn frame and form it. In the words of Jung (1969), the identity of an individual "is the unconscious as well as the conscious part of a person's psyche, which are seemingly opposites, but are in continued close interaction with each other, complementing and also compensating one another" (p. 69). This very definition appears to be perfect in relation to understanding the natures of the psyche of the two characters, OrmusCama and VinaApsara who are quite remarkable in terms of their dwellings and inclinations for one another.

Moreover, another notable aspect of the novel is the in-between state of the use of myth. In other words, the use of myth does not really fall in line with the actual one, but then, it is not false either. It places itself in a midway between the history and fiction which again substantiates the core idea of the novel. Also, the subtle switch between the real and the imaginary world also gets heightened when we find the lines which are stated below related to the unconscious state of mind of Ormus, "But he will spend his early days on the sea, within sight of land, which will remain just out of reach but which will listen, as though hypnotized, to his seductive, imagining voice" (The Ground Beneath Her Feet, p. 276). Thus, the novel stands out to be a proper mixture of historical elements coupled with the element of musical notes which greatly get substantiated by the attributes of human psyche at multiple levels in the novel.

\section{References:}

[1] Auden W.H. (1991).Mendelson E. The Collected Poems. UK: Vintage Books.

[2] Cupitt, Don. (1982). The World to Come. London: SCM Press.

[3] Freud S. (1923). The Ego and the Id. Standard Edition. London: Hogarth Press. (Translated

[4] by James Strachey). 
[5] Holmes, Su \& Sean Redmond.(2010). Editorial.A Journal in Celebrity Studies.Celebrity Studies, 1, 1, 1-10.

[6] Jung, Carl Gustav. (1969).The Structure and Dynamics of the Psyche. 1960. Ed. Sir Herbert Read, Michael Fordham, Gerhard Adler, William McGuire. Trans. R.F.C. Hull.2nd Edition.Vol. 8.The Collected Works. London and Henley: Routledge\&Kegan Paul.

[7] Lacan, Jacques. (1981). Book XI: The Four Fundamental Concepts of Psychoanalysis.Trans. Alan Sheridan. New York: Norton \& Company.

[8] McCutchion, David.(1972). "The Indian Novel in English."Studies in the Novel. 4.2. 304-320.

[9] Rushdie, Salman. (2000). The Ground Beneath Her Feet. London: Vintage.

[10] About the author: KinshukChakraborty completed his Master's Degree in English Literature from Assam University Silchar. $\mathrm{He}$ is currently pursuing his $\mathrm{PhD}$ from the Dept. of English, Assam University Silchar. His areas of interest are Indian Literatures in English, Literary Theory, Graphic Narratives, Speculative Fiction and Popular Literature. 